\title{
Corporate training as a strategic factor of competitiveness
}

\author{
Olga Mamatelashvili* , Elvira Mukhamadieva, and Tsiala Khisamova \\ Ufa State Petroleum Technological University, Kosmonavtov Str., 1, 450062Ufa, Russia
}

\begin{abstract}
In modern conditions, there is an urgent need for qualified personnel capable of forming a development strategy in a market innovative economy, mastering new types of business and new markets, and flexibly managing production and sales. The problem of special economic, legal and managerial education has become especially acute in a competitive environment. Business success is determined more and more not only by special knowledge in a specific area, but also by qualitatively new requirements for the company's management.The purpose of the article is to assess the effectiveness of corporate training, to identify factors directly or indirectly related to the training of company employees in order to increase their potential and thus ensure the economic security of the business. Also relevant is the search for ways to further develop corporate training, ensure its compliance with the modern requirements of a market economy, as well as change the attitude of specialists to their work on the basis of optimally planned training programs to attract the hidden resources of the company and the person.
\end{abstract}

\section{Introduction}

Personnel training in accordance with the requirements of the day is one of the important ways of the company's success in the conditions of the "knowledge economy" formation. The main task of training is the adaptation of personnel (and, above all, managers) to fundamentally new working conditions in the formation of a "knowledge economy" [1-5].

The formation of strategically important competencies is the product of the joint efforts of various groups of students, which together form the strategic advantage of the company. In this regard, the company should form and constantly modernize a corporate educational system focused on the market and solving a complex of labor, financial, economic, sociopsychological, educational, informational and other problems, ensuring effective production activity of a person and long-term success of the company. [6-8].

All this allows the company's management to have detailed information on various qualitative and quantitative aspects of personnel training and effectively manage this process. At the same time, two principles are observed - comparison with the external environment (competitors, industry, country) and with its own historical dynamics in the process of management analysis.

${ }^{*}$ Corresponding author: mar3169@yandex.ru 
The relevance of the problem under study is due to the fact that the level and pace of development of modern business have fundamentally changed the attitude to the training system as a service and an integral part of the personnel development process. The absolute imperative of the modern socio-economic development of society is the continuous growth of the intellectual and creative potential of a person. One of the main factors of such growth is the effective modernization of education in general and corporate education in particular.[9-10].

As noted, the most important condition for the development of a company, strengthening its authority in the market and increasing competitiveness are corporate knowledge, skills and abilities. The activities of the management for training specialists, the own work of employees in this direction, a powerful information retrieval system and the development of novations and innovations - all this works for the idea of constantly increasing and improving corporate knowledge[11-13].

In the digital economy, we are talking about the evolution of fragmented training towards an integral (systemic) concept of training company personnel. The main direction of the system development is to provide the company with well-trained (skilled) employees in accordance with the training strategy of the company's personnel [11-13].

The decisive factors for the continuous training of specialists are:

1. High competition. In this aspect, only modern systems and programs of engineering and management education make it possible to quickly respond to this by increasing labor productivity.

2.Changes in modern management technologies and information systems that requireconstant additional targeted training of personnel.

3. The introduction of new equipment and technologies in production, the growth of communication capabilities, which cause the elimination or change of some types of work, and the level of qualifications required for adaptation of existing managers and specialists is not guaranteed by their basic education.

4. A growing understanding by management that increasing the return on employees through continuous learning is more effective than attracting new employees.

\section{Materials and methods}

Already in the 70 s and 80 s of the XX century, the leading countries realized that successful competition in the world market, high rates of scientific and technological progress are impossible without constant training of personnel.

The new 21st century implies that significant investments in personnel development are required for maximum productivity and quality. The work of developing corporate training in large industrial corporations must become a continuous, carefully planned and controlled process. The idea of advanced education is largely consistent with the concept of lifelong learning and contributes to the fulfillment of the social role of a specialist in the life of a company.

To achieve these goals, in our opinion, it is necessary to solve two most important tasks:

-Identify the features of the impact of corporate training on the state of competitiveness of corporations.

- To propose a system for planning corporate training focused on the business environment and solving problems that ensure the effective operation of the corporation.

Corporate training allows the formation of uniform training principles for the company, which contribute to the development of professionalism, corporate spirit, fostering a sense of belonging to a team of company specialists organized to achieve a common goal. During the training process, attention is focused on the active participation of specialists in solving real problems of the company. After completing their studies, specialists continue to work in their organizations, where they apply the acquired knowledge and skills. In this sense, 
the interest of all members of the training group in the exchange of experience in solving specific problems based on the knowledge gained is of great importance. This approach makes it possible to combine theory and practice with visible benefits not only for the learners, but also for the structures that direct them to study. In addition, the very atmosphere of friendly relations between specialists participating in educational seminars gives them a positive charge and contributes to an increase in the effectiveness of this training model. [13-17].

\section{Results and discussion}

Determining the goals and content of corporate training allows you to outline the criteria for the subsequent assessment of the program, which determine its effectiveness in terms of the degree of compliance of the course content with the needs of the company, the timeliness of its implementation and economic security. Evaluation of the effectiveness of corporate programs also includes the collection of information on the skills and knowledge acquired by employees and on the degree of their satisfaction with the classes.All this helps to establish the objective compliance of the program with the intended goals. The most important indicator of the effectiveness of educational programs is the return on investment in training, as evidenced by an increase in productivity and quality of work, as well as the reliability of personnel.

Benefits of corporate training: the ability to provide training programs with a higher degree of adequacy and security to the needs of a particular company, flexibility and differentiation; participation in continuous training of a significant contingent of employees; less expensive way of teaching; great opportunities for individualization of training and the transition from theory to practice, when the educational material is directly related to work.

The development of the concept of continuous advanced learning in the company should be carried out taking into account:

- a system-integrated approach to its formation, including theoretical and practical aspects of the activities of specialists;

- the use of a block-modular structure, taking into account the continuity of professional educational programs, the logical sequence and interconnections of individual blocks;

- layout of the content of basic blocks based on integration methods (multilevel, multi-stage and multidisciplinary training programs);

- a differentiated approach to teaching various categories of students, depending on the nature and characteristics of their professional activities, a combination of group and individual forms of training, which implies the flexibility of organizational forms;

- two-stage control of the quality of training of students - input control of knowledge and verification of the assimilation of educational material by students on exit;

- advanced training, which significantly improves its quality; application of innovative learning.

Learning outcomes are enhanced by operational links between trainees aimed at broader exchange of information and dissemination of useful experience. In the activities of companies with geographically dispersed personnel, this factor plays a very important role and contributes to the development of a single corporate learning style and uniform corporate values. Such a corporate education provides a real opportunity to more effectively use the intellectual potential of managers and specialists, whose knowledge and experience become the property of colleagues and subordinates.

Corporate training enables managers of all levels to: 
- understand the global goals of the company, their impact on business goals, divisional goals and personal;

- determine the appropriate operational measures;

- determine the skills and qualifications necessary to strengthen the company's effective management system;

- set new goals and determine the appropriate skills for the implementation of each type of work;

- carry out an effective analysis of the company's activities, its key problems, answer burning questions, participate in discussions, and also consider the "response" of the team.

The preparation and implementation of corporate training programs, as a rule, consists of three components: an assessment of training needs, development of a program and an assessment of the results of the implemented program. Starting the development of a program with an assessment of the needs of the company's employees in certain knowledge and skills, they conduct surveys of managers and specialists of the company, discuss with them previous programs, study applications and needs for participation in them.

The next stage is the development of goals, content of the program, the choice of methods of conducting classes. The content of corporate training programs is determined by the tasks facing the company, which generally lead to the ultimate goal - to strengthen the current and future positions of the company in the market and its economic security.

The development of corporate training requires an annual analysis of the effectiveness of training programs, based on the results of which the content of training courses and programs is revised with a focus on practice. In defining new areas of knowledge required for the training of specialists (except for the disciplines of basic education), the emphasis should shift towards:

- obtaining practical and adapted knowledge of the intricacies of functional management, i.e., management of finances, material, human and time resources;

- fostering a broader professional culture that goes beyond narrowly specialized competence;

- personal indepth knowledge of the communication system;

- increasing competence in a specific field of activity;

- ability to use all technical resources and modern information technologies.

It can be argued that corporate training is especially effective in narrow practical courses, where managers, taking part in round tables, explain the key problems of the company, the prospects and challenges facing it, the company's goals and goals and objectives for individual managers and their teams, the importance of analyzing the work and the results achieved in the company.

In addition, senior leaders of management answer questions, facilitating the discussion, control the course of the round table, maintaining mutual interest, study the feedback received from the audience on the issues under consideration.

This approach allows for productive implementation of corporate training programs, forming a unified vision of the company's future and effective teams.

Thus, the main task of organizing, planning and coordinating work to improve the quality and content of the educational process is a prompt response to company requests.

\section{Conclusions}

As a result of the study, it was revealed that in a dynamically changing business environment, companies are faced with the problem of a shortage of highly qualified employees. One of the solutions to this problem is long-term planning of personnel development, including through advanced corporate training. Highly skilled workers become an important competitive advantage, enabling the company to achieve better 
results. Thus, personnel training becomes a part of the overall development strategy of the company, which ultimately determines this strategy.

Corporate training of personnel in accordance with the requirements of the day is a strategic factor in the development of the corporation.

Practice confirms a number of benefits of corporate training, which are supported by high-quality socio-economic benefits:

- economic: training within the company is cheaper;

- organizational and methodological: in the learning process, business contacts are established, creative cooperation arises;

- intellectual: in the process of studying, real problems are solved, specific situations are discussed, the professional level is raised, etc.;

- scientific and organizational: the creative potential of workers is activated, their orientation towards solving urgent problems, towards increasing independence in solving problems is growing.

The main tasks of corporate training are also strategically solved:

- creation of conditions for the implementation of the needs of the company's specialists in professional development;

- the formation of new thinking of the teaching staff;

- advanced training of managers and specialists in various areas of the management system.

This allows you to develop a flexible and broad-based corporate training.

Thus, corporate training, due to its organization according to the principle of "progressive specialization" (with a cumulative result), becomes a lever for the implementation of the company's strategy, an effective way of positive changes in personnel striving for professional development.

\section{References}

1. D.V. Didenko, Intellectually demanding economy: human capital in Russian and world socio-economic development, 408 (2015)

2. I.R. Kurnysheva, Features of the human capital of the Russian economy in the competitive world, 886 (2018)

3. T. Petrenko, Research of human capital as a factor of economic growth, 392 (2018)

4. D.O. Mongush, G.V. Panasenko, Science Alley, 3(10), 317 (2017)

5. A.A. Adamenko, E.B. Zolotukhina, V.A. Ulanov, I.V. Chizhankova, O.V. Mamatelashvilli, International Journal of Applied Business and Economic Research (2017)

6. S.A. Ilnitskiy, Young Scientist, 3, 418 (2018)

7. A.V. Pakhunov, Initiatives of the XXI century, 1-2, 31 (2017)

8. M.V. Gerasimov, Young Scientist, 5, 319 (2016)

9. A.A. Dovlekaeva, Young Scientist, 5, 154 (2017)

10. A.N. Kobysh, Problems of scientific thought, 1(4), 11(2017)

11. M.V. Clarin, Corporate training, mentoring, coaching: a tutorial, 288 (2018)

12. N.I. Klimova, D.K. Krasnoselskaya, D.R. Khamzina, Journal of Applied Economic Sciences (2018)

13. N.A. Semochkina, Bulletin of the Volgograd State Technical University, 7 (202), 39 (2017) 
14. Kuatpekova, A.K., Young scientist,1,389 (2016)

15. Popov, G.V., Bulletin of the Voronezh State University of Engineering Technologies, 4 (54), 137 (2018)

16. Zaika, M.M., Assessment of the level of development of personnel competencies in the corporate knowledge management system. - Dissertation of the candidate of economic sciences (2019)

17. Normazinin, S.V., A short collection of the best practices for training personnel from the BRICS countries // Autonomous non-profit organization "Agency for Strategic Initiatives to Promote New Projects", http://asi.ru/ 